\title{
Transcatheter Aortic Valve Implantation Compared with Surgical Aortic Valve Replacement in Patients with Anemia
}

Paola D’Errigo, ${ }^{1}$ Fausto Biancari, ${ }^{2}$ Stefano Rosato, ${ }^{1}$ Corrado Tamburino, ${ }^{3}$ Marco Ranucci, ${ }^{4}$ Gennaro Santoro, ${ }^{5}$ Marco Barbanti, ${ }^{3}$ Martina Ventura, ${ }^{6}$ Danilo Fusco, ${ }^{6}$ and Fulvia Seccareccia, ${ }^{1}$ on behalf of the OBSERVANT Research Group

${ }^{1}$ National Centre for Epidemiology, Surveillance and Health Promotion, Istituto Superiore di Sanità, Rome, Italy;

${ }^{2}$ Department of Surgery, Oulu University Hospital, Oulu, Finland;

${ }^{3}$ Division of Cardiology, Ferrarotto Hospital, University of Catania, Catania, Italy

${ }^{4}$ Department of Cardiothoracic and Vascular Anesthesia and ICU - IRCCS Policlinico San Donato, San Donato Milanese, Milan, Italy

${ }^{5}$ Division of Cardiology, Careggi Hospital, Florence, Italy

${ }^{6}$ Department of Epidemiology of Lazio Regional Health Service, Rome, Italy

Word count: 5336 words

For correspondence:

Stefano Rosato, MSc,

Surveillance and Health Promotion,

National Centre for Epidemiology,

Istituto Superiore di Sanità,

Via Giano della Bella 34

00161 Rome, Italy

Phone: +3906 44404237

Fax: +390644404170

E-mail: stefano.rosato@iss.it 


\section{ABSTRACT}

Objectives: We aimed to compare the early and mid-term results of patients with preoperative anemia undergoing transcatheter (TAVI) and surgical aortic valve replacement (SAVR).

Methods: Patients with severe aortic valve stenosis undergoing TAVI and SAVR from the OBSERVANT study were the subjects of this analysis. Anemia was defined as a preoperative hemoglobin level $<13.0 \mathrm{~g} / \mathrm{dL}$ in men and $<12.0 \mathrm{~g} / \mathrm{dL}$ in women.

Results: Preoperative anemia was observed in $58.3 \%$ of TAVI patients and in $31.4 \%$ of SAVR patients. Anemia was an independent predictor of 3-year mortality after either TAVI (HR1.37, 95\%CI 1.12-1.68) or SAVR (HR 1.63, 95\%CI 1.37-1.99). Propensity score one-to-one matching resulted in 302 pairs of anemic patients with similar baseline characteristics. Thirty-day mortality was $3.6 \%$ after SAVR and 3.3\% after TAVI ( $\mathrm{p}=0.81)$. Stroke rate similar in the study groups (SAVR, $1.3 \%$ vs. TAVI $2.0 \%, \mathrm{p}=0.53)$. The rates of permanent pace-maker implantation (18.6\% vs. $3.0 \%, \mathrm{p}<0.001)$, major vascular damage $(5.7 \%$ vs. $0.4 \%, \mathrm{p}<0.001)$ and mild-to-severe paravalvular regurgitation $(47.4 \%$ vs. $9.3 \% \mathrm{p}<0.001)$ were significantly higher after TAVI compared with SAVR. However, the incidence of cardiogenic shock ( $2.0 \%$ vs. $6.8 \%, p=0.003)$, acute kidney injury (AKIN stages 1-3: $27.9 \%$ vs. $50.7 \%, \mathrm{p}<0.001)$, blood transfusion $(38.6 \%$ vs. $70.0 \%, \mathrm{p}<0.001)$ and the number of units of blood transfusion (mean, $0.8 \pm 1.5$ vs. $3.2 \pm 3.8, p<0.001$ ) were significantly lower after TAVI compared with SAVR. These translated into a shorter stay in the intensive care unit after TAVI (mean, $3.2 \pm 4.3$, vs. $4.7 \pm 9.6$ days, $\mathrm{p}=0.012$ ). Among these propensity score matched cohorts, 1-, 2- and 3-year survival were $83.6 \%, 79.8 \%$ and $74.0 \%$ after SAVR and $86.0 \%, 78.4 \%$ and $66.3 \%$ after TAVI, respectively (stratified log-rank test $\mathrm{p}=0.065)$. One-, two- and three-year freedom from MACCE were $79.8 \%, 74.7 \%$ and $67.6 \%$ after SAVR and $80.9 \%, 71.3 \%$ and $58.7 \%$ after TAVI, respectively (stratified log-rank test $\mathrm{p}=0.049$ ). 
Conclusions: Anemia is an independent predictor of mid-term mortality after either TAVI or SAVR. Despite a higher risk of perioperative transfusion and acute kidney injury, anemic patients undergoing SAVR have a better mid-term outcome compared with those undergoing TAVI. These results suggest that TAVI is not superior to conventional surgery in patients with anemia.

Abstract word count: 346 words.

Key Words: Anemia; anemic; aortic valve stenosis; TAVR; TAVI; aortic valve replacement; conventional; surgical. 


\section{INTRODUCTION}

Anemia is associated with decreased early and late survival after cardiac surgery (1). The negative prognostic impact of decreased preoperative levels of hemoglobin is likely due to a synergistic contribution of comorbidities underlying anemia (2). However, other mechanisms may be implicated, like severe hemodilution during cardiopulmonary bypass (CPB) and the use of blood products to correct hemodilution and bleeding-related anemia (3). Preoperative use of erythropoiesis stimulating agents and iron would be logical measures to correct anemia before cardiac surgery. Indeed, this approach along with meticulous surgical technique and reinfusion of shed blood allows transfusion free cardiac surgery in Jehovah's witnesses without compromising the outcome of these patients (4). However, the perceived increased risk of thromboembolism related to a sudden increased of hemoglobin and the lack of data on the safety and efficacy of these strategies (5) along with the danger associated with delayed surgery prevent the preoperative optimization of hemoglobin level in daily practice. Still, anemia renders difficult the decision-making process in patients with severe aortic valve stenosis and may favor transcatheter aortic valve implantation (TAVI) with respect to surgical aortic valve replacement (SAVR), because of its related decreased risk of major bleeding and need for transfusions (6). The prognostic impact of anemia in patients undergoing aortic valve replacement and the potential benefits of TAVI over SAVR in anemic patients are investigated in the present multicenter study.

\section{MATERIAL AND METHODS}

Study design and data collection

OBSERVANT (OBservational Study of Effectiveness of avR-taVi procedures for severe Aortic steNosis Treatment) is a national observational, prospective, multicenter, cohort study that enrolled consecutive patients undergoing TAVI or SAVR for severe aortic valve stenosis at 93 Italian cardiology/cardiac surgery centers between December 2010 and June 2012. Details on the study 
design, patient eligibility criteria and data collection modalities are reported elsewhere (7). This study was coordinated by the Italian National Institute of Health and led in cooperation with the Italian Ministry of Health, the National Agency for Regional Health Services, Italian Regions, and Italian scientific societies and federations representing Italian professionals involved in the management of aortic valve stenosis. The complete list of executive working group, participating centers and investigators are reported in the Appendix. In the participating hospitals, both SAVR and TAVI could have been offered to patients with severe aortic valve stenosis. Data on demographic characteristics, health status prior to intervention, comorbidities, and complete information on the type of intervention were collected into a standardized online datasheet on a password-protected website. Collected data were stored and analyzed at the Italian National Institute of Health. CoreValve (Medtronic, Minnesota, USA) and Sapien XT (Edwards Lifesciences, Irvine, California, USA) valve prostheses were implanted in these patients. Data auditing was performed by independent observers following specific standard operating procedures. They monitored the participating hospitals to assess the completeness of the enrolled cohort and compared the collected data with those of the original clinical records. The study protocol has been approved by the Ethical Committee of each participating center and patients gave their informed consent to participate in this study.

\section{Inclusion criteria}

The study population included consecutive adult patients admitted with a diagnosis of severe aortic valve stenosis (defined as an aortic valve area $<1 \mathrm{~cm}^{2}$, maximum aortic velocity $>4 \mathrm{~m} / \mathrm{s}$, or mean pressure gradient $>40 \mathrm{mmHg}$ ) and requiring an aortic valve replacement. The aim of the present analysis was to evaluate the impact of anemia on the outcome after TAVI and SAVR in separate cohorts. Anemia was defined as a hemoglobin level $<13.0 \mathrm{~g} / \mathrm{dL}$ in men and $<12.0 \mathrm{~g} / \mathrm{dL}$ in women (8). Anemia was further classified into mild (hemoglobin 11.0-12.9 g/dL in men and 11.0- 
$11.9 \mathrm{~g} / \mathrm{dL}$ in women), moderate (hemoglobin $8.0-10.9 \mathrm{~g} / \mathrm{dL}$ in men and 8.0-10.9 $\mathrm{g} / \mathrm{dL}$ in women) and severe anemia (hemoglobin $<8.0 \mathrm{~g} / \mathrm{dL}$ in men and women) according to the WHO criteria (8). After assessing the impact of anemia in these two cohorts, a comparative analysis of the immediate and intermediate outcome after TAVI and SAVR was performed. In order to guarantee the comparability of the subjects undergoing TAVI or SAVR, patients with porcelain aorta, hostile chest and active endocarditis as well as those undergoing any combined coronary procedure,emergency procedure or a TAVI performed through a transapical approach were excluded from this analysis.

\section{Outcome end-points and follow-up.}

Thirty-day and 3-year survival were the primary end-points of this analysis. Secondary endpoints were in-hospital adverse events such as stroke, vascular complications, bleeding and acute kidney injury. Stroke was defined as any focal deficit lasting $>24$ hours, or focal deficit lasting $<24$ hours with positive neuro-imaging studies. Vascular complications were defined as any access site complication requiring surgical or percutaneous vascular intervention. Severity of bleeding was estimated as the proportion of patients who received red blood cell transfusion and as the number of units of transfused red blood cells. Acute kidney injury was classified in three stages according to the AKIN definition criteria and taking into consideration only the baseline and postoperative serum creatinine levels (9). Other secondary outcome end-points were major adverse cardiac and cerebrovascular events (MACCE) at 3 years. MACCE were defined as the composite end-point including any of the following adverse events: death from any cause, stroke, myocardial infarction, percutaneous coronary intervention (PCI) and/or CABG. An administrative follow-up has been set up for each enrolled patient through a record linkage with the National Hospital Discharged Records database for in-hospital events and with the Tax Registry Information System for information on survival. 


\section{Statistical analysis}

The impact of anemia on 3-year mortality was evaluated separately in the TAVI and SAVR cohorts by Cox proportional hazards analysis. A stepwise approach was used to select variables to be included in the model. Exploratory and interaction analyses were performed and showed that the TAVI cohort had a significantly higher operative risk than the SAVR cohort. Therefore, a propensity score matching method was employed to identify patients undergoing SAVR and TAVI with similar baseline characteristics (10). Propensity score was estimated by non-parsimonious logistic regression model with the treatment method as the dependent variable and the following variables as covariates: age, gender, body mass index, smoking habit, frailty status, baseline hemoglobin, baseline albumin, previous percutaneous coronary intervention, previous balloon aortic valvuloplasty, previous cardiac surgery, previous operation on the aortoiliac arteries; chronic dialytic treatment, diabetes, chronic obstructive pulmonary disease, oxygen therapy, previous myocardial infarction, peripheral arteriopathy, estimated glomerular filtration rate, critical preoperative state, unstable angina, neurological dysfunction, pulmonary hypertension (systolic pulmonary arterial pressure $>60 \mathrm{~mm} \mathrm{Hg}$ ), chronic liver disease, active neoplastic disease, New York Heart Association class, coronary artery disease, urgent operation, left ventricular ejection fraction, mitral valve regurgitation as well as mean and peak transvalvular gradient.

One-to-one propensity score matching was performed employing the nearest neighbour method and a caliper of 0.2 of the standard deviation of the logit of the propensity score (11). To evaluate the balance between the matched groups the t-test for paired sample for continuous variables, the McNemar test for dichotomous variables, the Stuart-Maxwell test for categorical variables, and the analysis of the standardized differences after matching have been used. The same tests have been used to test differences in the early adverse events of propensity score matched groups. When a patient of a pair was lost to follow-up and the matched patient was still alive (or free from events 
when considering the MACCE outcome end-point), the time of observation of both patients was truncated at the time of the last observation of the lost patient to guarantee the comparability between the two groups. Differences in the outcomes at 3 years have been evaluated by the KaplanMeier method with the Klein-Moeschberger stratified log rank test (12). Tests were two-sided and a $\mathrm{p}<0.05$ was considered statistically significant. Statistical analyses were performed using the SAS statistical package, version 9.4 (SAS Institute Inc., Cary, NC, USA)

\section{RESULTS}

The OBSERVANT study includes 7,618 patients who underwent either TAVI or SAVR. For the purposes of this study, 5135 patients fulfilled the inclusion criteria and were the subjects of this analysis. From this cohort of patients, 3762 patients (73.3\%) underwent SAVR and 1373 (26.7\%) underwent TAVI. The prevalence of anemia as defined by the WHO criteria was $58.3 \%$ in the TAVI group and $31.4 \%$ in the SAVR group. Separate multivariate analyses in the TAVI and SAVR cohorts showed that preoperative anemia was an independent predictor of 3-year mortality after either TAVI (HR 1.37, 95\%CI 1.12-1.68) and SAVR (HR 1.63, 95\%CI 1.37-1.99) (Table 1). These findings were confirmed in interaction analysis (TAVI, HR 1.38, 95\%CI 1.13-1.68; SAVR, HR $1.70,95 \%$ CI 1.40-2.07; interaction p-value $=0.134)$.

Among anemic patients, 1180 underwent SAVR and 800 underwent TAVI. Significant differences in baseline variables and operative risk were observed in these two cohorts (logistic EuroSCORE, TAVI $14.6 \pm 12.5 \%$ vs. SAVR 5.7 $\pm 5.8 \%, \mathrm{p}<0.001$; EuroSCORE II, TAVI 7.7 $\pm 8.3 \%$ vs. SAVR 3.0 $\pm 3.5 \%, \mathrm{p}<0.001)$. Therefore, a propensity score for estimation of the risk of being assigned to the TAVI or SAVR was calculated. Propensity score one-to-one matching resulted in 302 pairs without significant differences in baseline characteristics (Tables 2,3) as estimated by standardized differences (Figure 1). Only one of the covariates had a post-match standardized 
difference $>10 \%$, which indicates an excellent covariate balance. The diameter of the aortic annulus significantly differed between the study groups likely because of differences in the methods of measurement (Figure 1).

\section{Outcomes}

Early adverse events are summarized in Table 4 . Thirty-day mortality was $3.6 \%$ after SAVR and $3.3 \%$ after TAVI $(\mathrm{p}=0.81)$. Stroke rate was rather low and similar in the two study groups (SAVR, $1.3 \%$ vs. TAVI $2.0 \%, \mathrm{p}=0.53)$. The rates of permanent pace-maker implantation (18.6\% vs. $3.0 \%, \mathrm{p}<0.001)$, major vascular damage $(5.7 \%$ vs. $0.4 \%, \mathrm{p}<0.001)$, mild-to-severe paravalvular regurgitation $(50.0 \%$ vs. $9.8 \%, \mathrm{p}<0.001)$ and moderate-to-severe paravalvular regurgitation $(6.3 \%$ vs. $1.7 \%, \mathrm{p}=0.005$ ) were significantly higher after TAVI compared with SAVR. However, the proportion of cardiogenic shock $(2.0 \%$ vs. $6.8 \%, \mathrm{p}=0.003)$, patients who received blood transfusion (38.6\% vs. $70.0 \%, \mathrm{p}<0.001$ ), number of units of blood transfusion (mean, $0.8 \pm 1.5$ vs. $3.2 \pm 3.8$, $\mathrm{p}<0.001$ ), and acute kidney injury (AKIN stages $1-3: 27.9 \%$ vs. $50.7 \%, \mathrm{p}<0.001$ ) were significantly lower after TAVI compared with SAVR. These translated in a shorter stay in the intensive care unit after TAVI (mean, $3.2 \pm 4.3$, vs. $4.7 \pm 9.6$ days, $\mathrm{p}=0.012$ ). Furthermore, TAVI was associated also with lower mean transvalvular gradient (mean, $10.6 \pm 6.4 \mathrm{mmHg}$ vs. $13.2 \pm 6.5 \mathrm{mmHg}, \mathrm{p}<0.001$ ) and peak transvalvular gradient (mean, $19.5 \pm 10.8 \mathrm{mmHg}$ vs. $24.5 \pm 11.1 \mathrm{mmHg}, \mathrm{p}<0.001$ ).

Among these propensity score matched cohorts, 1-, 2- and 3-year survival were $83.6 \%, 79.8 \%$ and $74.0 \%$ after SAVR and $86.0 \%, 78.4 \%$ and $66.3 \%$ after TAVI, respectively (stratified log rank test, $\mathrm{p}=0.065$ ) (Figure 2). One-, two- and three-year freedom from MACCE were 79.8\%, 74.7\% and $67.6 \%$ after SAVR and $80.9 \%, 71.3 \%$ and $58.7 \%$ after TAVI, respectively (stratified log rank test, $\mathrm{p}=0.049$ ) (Figure 2). The incidence of adverse events (stroke, myocardial infarction and coronary revascularization) at 3-year follow-up are reported in Table 5. 


\section{DISCUSSION}

The present study showed that preoperative anemia is rather common in patients with severe aortic valve stenosis and this is likely due to the advanced age and associated comorbidities of this fragile patient population. Furthermore, Heyde's syndrome and coagulopathy may account as frequent causes of anemia in patients with severe aortic valve stenosis [13]. In fact, the prevalence of anemia in patients undergoing TAVI has been reported ranging from $42 \%$ to $67 \%$ in different centers [14-17] and it is higher than in patients undergoing general cardiac surgery, which has been estimated being $31 \%$ in a large UK study [18].

In the present study, anemia had an independent, negative prognostic impact on midterm outcome after either TAVI or SAVR. Also a few recent studies showed that preoperative anemia before TAVI was associated with poorer mid-term survival $[14,15,19]$, and the adjusted risk estimates of 1-year mortality ranged from 1.44 to $2.10[14,15]$. Similarly, anemia is associated with increased early and late mortality also after cardiac surgery [1,20-23]. Whether the negative effect of preoperative anemia is related to suboptimal oxygen delivery and is aggravated by the use of blood transfusion or a combination of both is still a matter of debate [24]. In view of the significant prevalence of preoperative anemia and the risk of severe bleeding and need of transfusion, a policy of optimization of hemoglobin level with administration of iron intravenously and erythropoiesis stimulating agents would be a logical approach before aortic valve replacement. However, the lack of data on its safety formally prevents a widespread of this strategy [25].

In this scenario of uncertainty regarding the treatment of preprocedural anemia, anemic patients with severe aortic valve stenosis may be assigned to a less invasive treatment such as TAVI in order to reduce the risk of significant bleeding and, consequently, the need of transfusion which are common during conventional cardiac surgery and the use of cardiopulmonary bypass. However, the 
present results indicate that, despite its minimally invasive nature, a large number of patients (39\%) undergoing TAVI still required blood transfusion. The proportion of patients who received blood transfusion and their amount were anyway significantly larger in the SAVR cohort. In turn, patients undergoing conventional surgery had an increased rate of acute kidney injury and longer stay in the intensive care unit, but they did not have an increased risk of other major complications. Indeed, these results confirmed the particularly deleterious effect of severe hemodilution on postoperative renal function (26).

On the contrary, the risk of permanent pace-maker implantation $(18.6 \%$ vs. $3.0 \%, \mathrm{p}<0.001)$, major vascular damage $(5.7 \%$ vs. $0.4 \%, \mathrm{p}<0.001)$ and mild-to-severe paravalvular regurgitation $(47.4 \%$ vs. $9.3 \% \mathrm{p}<0.001)$ were significantly higher after TAVI compared with SAVR. At 3 years, TAVI was associated also with a significantly lower freedom from MACCE and a trend toward decreased survival. This is the first study comparing TAVI and SAVR in patients with anemia and therefore no data are available to confirm and further interpret the present findings. We speculate that, despite the increased risk of bleeding and need of perioperative transfusion, conventional surgical treatment of severe aortic valve stenosis had a better survival and freedom from MACCE because of its related lower risk of paravalvular regurgitation and permanent pacemaker implantation. This may compensate for the higher renal risk related to hemodilution on cardiopulmonary bypass. Furthermore, it is unclear whether these two treatment methods have a different impact on recovery of anemia after aortic valve replacement. De Backer and colleagues [16] reported on anemia recovery in only $40 \%$ of patients one year after TAVI. It is unknown whether paravalvular regurgitation, more frequently observed after TAVI, may have an effect on recovery of anemia in these patients. On the other hand, SAVR has been shown to be effectively revert coagulopathy and severe anemia also in patients with Heyde's syndrome [27]. Further studies 
are needed to elucidate the effects of TAVI and SAVR on the recovery of anemia and their impact on late outcome in anemic patients

\section{Study limitations}

The results of this study can be affected by a number of limitations which deserve to be acknowledged. First, this is not a randomized study and in order to compensate for the potential selection bias and differences in baseline characteristics we performed a propensity score matching. The results of propensity score matching may still be biased by confounders not taken into account in this study. However, conditions contraindicating SAVR were excluded from this analysis. Second, the definition of anemia probably is not appropriate for patients undergoing major surgical procedures. However, the adopted cutoff of hemoglobin level has been widely in use in clinical research as a valid parameter for definition of anemia and different degree of anemia were well balanced between the study groups. Third, we do not have data either on perioperative nadir level of hemoglobin or after discharge. This limitation prevents analysis of the impact of severe perioperative anemia and of persistent anemia after the procedure on the early and late outcome.

\section{CONCLUSIONS}

The results of this study confirm that patients with anemia have a poorer outcome after either TAVI or SAVR. The significant prevalence and negative prognostic impact of anemia among patients requiring aortic valve replacement suggests the urgent need of adequately performed studies to evaluate the benefit of preoperative optimization of hemoglobin level before TAVI and SAVR. Despite a higher risk of perioperative blood transfusion and acute kidney injury, anemic patients undergoing SAVR seem to have a better intermediate outcome compared with those undergoing TAVI. These results suggest that TAVI is not superior to SAVR in patients with anemia. 


\section{Acknowledgements}

The authors thank Gabriella Badoni for her technical support in the organizational phases of the study.

\section{Funding Sources}

The OBSERVANT Study was supported by a grant (Fasc. 1M30) from Italian Ministry of Health and Istituto Superiore di Sanità.

\section{Conflict of interest}

Prof. Tamburino receives honorary fees from Medtronic and Abbott; Dr. Barbanti is consultant for Edwards Lifesciences; there is no potential conflict of interest related to the matter of the article for any other coauthor.

\section{REFERENCES}

[1] Karkouti K, Wijeysundera DN, Beattie WS. Risk associated with preoperative anemia in cardiac surgery: a multicenter cohort study. Circulation 2008;117:478-484.

[2] Adamson JW, Longo DL. Anemia and polycythemia. In: Longo DL, Kasper DL, Jameson JL, Fauci AS, Hauser SL, Loscalzo J (eds.) Harrison's principles of internal medicine. New York, McGraw-Hill, 2012;57:448-457.

[3] Ranucci M, Carboni G, Cotza M, Bianchi P, Di Dedda U, Aloisio T; Surgical and Clinical Outcome Research (SCORE) Group. Hemodilution on cardiopulmonary bypass as a determinant of early postoperative hyperlactatemia. PLoS One 2015;10:e0126939. 
[4] Pattakos G, Koch CG, Brizzio ME, Batizy LH, Sabik JF 3rd, Blackstone EH, et al. Outcome of patients who refuse transfusion after cardiac surgery: a natural experiment with severe blood conservation. Arch Intern Med 2012;172:1154-60.

[5] Lin DM, Lin ES, Tran MH. Efficacy and safety of erythropoietin and intravenous iron in perioperative blood management: a systematic review. Transf Med Rev 2013;27:221-234.

[6] Tamburino C, Barbanti M, D'Errigo P, Ranucci M, Onorati F, Covello RD, et al. 1-year outcomes after transfemoral transcatheter or surgical aortic valve replacement: results from the Italian OBSERVANT study. J Am Coll Cardiol 2015;66:804-12.

[7] D'Errigo P, Fusco D, Grossi C, Ramondo AB, Ranucci M, Santini F, et al. OBSERVANT: observational study of appropriateness, efficacy and effectiveness of AVR-TAVI procedures for the treatment of severe symptomatic aortic stenosis. Study protocol. G Ital Cardiol 2010;11:897-909. [8] World Health Organization. Haemoglobin concentrations for the diagnosis of anaemia and assessment of severity. WHO [published 2011, accessed 20 March 2016]. Available from: http://www.who.int/vmnis/indicators/haemoglobin.pdf [9] Mehta RL, Kellum JA, Shah SV, Molitoris BA, Ronco C, Warnock DG, et al. Acute Kidney Injury Network: report of an initiative to improve outcomes in acute kidney injury. Crit Care 2007;11:R31.

[10] Rosenbaum PR, Rubin DB. The central role of the propensity score in observational studies for causal effects. Biometrika 1983;70:41-55.

[11] Austin PC. Optimal caliper widths for propensity-score matching when estimating differences in means and differences in proportions in observational studies. Pharm Stat 2011;10: 150-161. [12] Klein JP, Moeschberger ML. Survival analysis: techniques for censored and truncated data. New York, Springer-Verlag, 1997.

[13] Massyn MW, Khan SA. Heyde syndrome: a common diagnosis in older patients with severe aortic stenosis. Age Ageing 2009;38:267-70. 
[14] Van Mieghem NM, Nuis RJ, Tzikas A, Piazza N, Schultz C, Serruys PW, et al. Prevalence and prognostic implications of baseline anaemia in patients undergoing transcatheter aortic valve implantation. EuroIntervention 2011;7:184-91.

[15] Nuis RJ, Sinning JM, Rodés-Cabau J, Gotzmann M, van Garsse L, Kefer J, et al. Prevalence, factors associated with, and prognostic effects of preoperative anemia on short- and long-term mortality in patients undergoing transcatheter aortic valve implantation. Circ Cardiovasc Interv 2013;6:625-634.

[16] De Backer O, Arnous S, Lønborg J, Brooks M, Biasco L, Jönsson A, et al. Recovery from anemia in patients with severe aortic stenosis undergoing transcatheter aortic valve implantation Prevalence, predictors and clinical outcome. PloS ONE 2014;9:e114038.

[17] Shuvy M, Mewa J, Wolff R, Hutson J, Austin PC, Bentley D, et al. Preprocedure anemia management decreases transfusion rates in patients undergoing transcatheter aortic valve implantation. Can J Cardiol. 2015 (in press)

[18] Klein AA, Collier TJ, Brar MS, Evans C, Hallward G, Fletcher SN, et al. The incidence and importance of anaemia in patients undergoing cardiac surgery in the UK - the first Association of Cardiothoracic Anaesthetists national audit. Anaesthesia. 2016 (in press).

[19] Arai T, Morice MC, O’Connor SA, Yamamoto M, Eltchaninoff H, Leguerrier A, et al. Impact of pre- and post-procedural anemia on the incidence of acute kidney injury and 1-year mortality in patients undergoing transcatheter aortic valve implantation (from the French Aortic National CoreValve and Edwards 2 [FRANCE 2] Registry). Catheter Cardiovasc Interv 2015;85:1231-1239. [20] Elmistekawy E, Rubens F, Hudson C, McDonald B, Ruel M, Lam K, et al. Preoperative anaemia is a risk factor for mortality and morbidity following aortic valve surgery. Eur $\mathbf{J}$ Cardiothorac Surg 2013;44:1051-5. 
[21] van Straten AH, Hamad MA, van Zundert AJ, Martens EJ, Schönberger JP, de Wolf AM. Preoperative hemoglobin level as a predictor of survival after coronary artery bypass grafting: a comparison with the matched general population. Circulation 2009;120:118-25.

[22] Engoren M, Schwann TA, Habib RH, Neill SN, Vance JL, Likosky DS. The independent effects of anemia and transfusion on mortality after coronary artery bypass. Ann Thorac Surg 2014;97:514-20.

[23] Fowler AJ, Ahmad T, Phull MK, Allard S, Gillies MA, Pearse RM. Meta-analysis of the association between preoperative anaemia and mortality after surgery. Br J Surg 2015;102:1314-24. [24] Loor G, Rajeswaran J, Li L, Sabik JF 3rd, Blackstone EH, McCrae KR, et al. The least of 3 evils: exposure to red blood cell transfusion, anemia, or both? J Thorac Cardiovasc Surg $2013 ; 146: 1480-1487$.

[25] D'Ambra MN, FitzGerald D, Kaufman RM, Shekar P. Blood conservation: why aren't we doing this for everyone? J Thorac Cardiovasc Surg 2015;150:984-5.

[26] Ranucci M, Aloisio T, Carboni G, Ballotta A, Pistuddi V, Menicanti L, Frigiola A; Surgical and Clinical Outcome REsearch (SCORE) Group. Acute kidney injury and hemodilution during cardiopulmonary bypass: a changing scenario. Ann Thorac Surg 2015;100:95-100.

[27] Tamura T, Horiuchi H, Imai M, Tada T, Shiomi H, Kuroda M, et al. Unexpectedly high prevalence of acquired von Willebrand syndrome in patients with severe aortic stenosis as evaluated with a novel large multimer index. J Atheroscler Thromb 2015;22:1115-23.

\section{Legend to figures}

Figure 1. Graphical representation of absolute standardized differences before and after propensity score matching comparing baseline covariates of patients undergoing transcatheter aortic valve implantation and surgical aortic valve replacement. Post-match standardized difference $<0.1$ indicates excellent covariate balance. 
Figure 2. Intermediate survival (Log rank test by Klein-Moeschberger: $p=0.0075$ ) and freedom from major adverse cardiac and cerebrovascular events (MACCE) (Log rank test by KleinMoeschberger: $\mathrm{p}=0.0023$ ) in propensity score matched pairs of patients with anemia after transcatheter (TAVI, red line) or surgical aortic valve replacement (SAVR, blue line) for severe aortic valve stenosis. 
Table 1. Independent predictors of 3-year mortality after transcatheter (TAVI) and surgical aortic valve replacement (SAVR).

\begin{tabular}{llll}
\hline Variables & $H R$ & $(95 \% C I)$ & P-value \\
\hline
\end{tabular}

TAVI

$\begin{array}{lccc}\text { Anemia } & 1.37 & (1.12-1.68) & 0.0024 \\ \text { Age } & 0.99 & (0.98-1.01) & 0.3918 \\ \text { Female gender } & 0.72 & (0.60-0.87) & 0.0008 \\ \text { Estimated glomerular filtration rate } & 0.99 & (0.98-0.99) & <.0001 \\ \text { Active neoplastic disease } & 2.22 & (1.55-3.18) & <.0001 \\ \text { Frailty (moderate-severe) } & 1.45 & (1.19-1.78) & 0.0003 \\ \text { New York Heart Association classes } & & & \\ \quad \text { Class 2 } & & & 0.2303 \\ \quad \text { Class 3 } & 0.76 & (0.49-1.19) & 0.5546 \\ \quad \text { Class 4 } & 0.88 & (0.58-1.35) & 0.3281\end{array}$

SAVR

$\begin{array}{lccc}\text { Anemia } & 1.63 & (1.34-1.99) & <.0001 \\ \text { Age } & 1.06 & (1.05-1.08) & <.0001 \\ \text { Female gender } & 0.85 & (0.70-1.04) & 0.1159 \\ \text { Prior interventions on the aortoiliac arteries } & 1.92 & (1.14-3.23) & 0.0140 \\ \text { Pulmonary disease } & 1.77 & (1.37-2.31) & <.0001 \\ \text { Estimated glomerular filtration rate } & 0.99 & (0.99-1.00) & 0.0157 \\ \text { Dialysis } & 3.46 & (1.83-6.54) & 0.0001 \\ \text { Chronic liver disease } & 1.82 & (1.13-2.93) & 0.0135 \\ \text { Frailty (moderate-severe) } & 1.77 & (1.28-2.44) & 0.0005\end{array}$


Coronary disease

$\begin{array}{lccc}1 \text { vessel } & 1.24 & (0.89-1.73) & 0.1951 \\ 2 \text { vessels } & 0.85 & (0.47-1.55) & 0.5994 \\ 3 \text { vessels } & 1.97 & (1.15-3.38) & 0.0134\end{array}$


Table 2. Baseline clinical characteristics of propensity score matched pairs of patients with anemia undergoing transcatheter (TAVI) or surgical aortic valve replacement (SAVR).

\begin{tabular}{|c|c|c|c|}
\hline & $\begin{array}{l}\text { SAVR } \\
n=302\end{array}$ & $\begin{array}{l}\text { TAVI } \\
n=302\end{array}$ & p-value \\
\hline Age (years \pm SD) & $80.0 \pm 5.3$ & $80.4 \pm 6.5$ & 0.318 \\
\hline Male, n (\%) & $169(56.0)$ & $166(55.0)$ & 0.803 \\
\hline Hemoglobin (g/dL) & $10.6 \pm 1.1$ & $10.6 \pm 0.9$ & 0.720 \\
\hline \multicolumn{4}{|l|}{ Severity of anemia* } \\
\hline Mild anemia & $183(60.6)$ & $178(58.9)$ & 0.741 \\
\hline Moderate anemia & $118(39.1)$ & $124(41.1)$ & \\
\hline Severe anemia & $1(0.3)$ & 0 & \\
\hline $\mathrm{BMI}\left(\mathrm{kg} / \mathrm{m}^{2} \pm \mathrm{SD}\right)$ & $26.1 \pm 4.1$ & $26.3 \pm 5.1$ & 0.569 \\
\hline Albumin $(\mathrm{g} / \mathrm{dL} \pm \mathrm{SD})$ & $3.5 \pm 0.9$ & $3.5 \pm 0.8$ & 0.479 \\
\hline Diabetes mellitus, n (\%) & $88(29.1)$ & $89(29.5)$ & 0.930 \\
\hline eGFR $\left(\mathrm{mg} / \mathrm{min} / 1.73 \mathrm{~m}^{2} \pm \mathrm{SD}\right)$ & $57 \pm 21$ & $56 \pm 22$ & 0.874 \\
\hline Chronic dialytic treatment, $\mathrm{n}(\%)$ & $9(3.0)$ & $7(2.3)$ & 0.593 \\
\hline Smoking history, n (\%) & $34(11.3)$ & $30(9.9)$ & 0.579 \\
\hline Neurologic dysfunction, n (\%) & $18(6.0)$ & $18(6.0)$ & 1.000 \\
\hline Chronic liver disease, n (\%) & $14(4.6)$ & $13(4.3)$ & 0.835 \\
\hline Active neoplastic disease, n (\%) & $8(2.6)$ & $9(3.0)$ & 0.796 \\
\hline Peripheral arteriopathy, n (\%) & $45(14.9)$ & $55(18.2)$ & 0.286 \\
\hline Pulmonary disease, n (\%) & $72(23.8)$ & $69(22.8)$ & 0.782 \\
\hline Pulmonary hypertension, n (\%) & $37(12.2)$ & $34(11.3)$ & 0.705 \\
\hline Oxygen therapy, n (\%) & $9(3.0)$ & $9(3.0)$ & 1.000 \\
\hline Previous cardiac surgery, n (\%) & $29(9.6)$ & $31(10.2)$ & 0.768 \\
\hline Previous op. on the aorta, $\mathrm{n}(\%)$ & $6(2.0)$ & $7(2.3)$ & 0.782 \\
\hline Previous BAV, n (\%) & $12(4.0)$ & $12(4.0)$ & 1.000 \\
\hline Previous AMI, n (\%) & $32(10.6)$ & $38(12.6)$ & 0.446 \\
\hline
\end{tabular}




$\begin{array}{llll}\text { Previous PCI, n (\%) } & 45(14.9) & 45(14.9) & 1.000 \\ \text { Coronary artery disease, n (\%) } & 59(19.5) & 56(18.5) & 0.519 \\ \quad \text { One-vessel disease } & 28(9.3) & 33(10.9) & \\ \quad \text { Two-vessels disease } & 15(5.0) & 14(4.6) & \\ \quad \text { Three-vessels disease } & 16(5.3) & 9(3.0) & \\ \text { NYHA classes, n (\%) } & & & 0.976 \\ \quad \text { I } & 17(5.6) & 15(5.0) & \\ \quad \text { II } & 109(36.1) & 107(35.4) & \\ \quad \text { III } & 144(47.7) & 147(48.7) & \\ \quad \text { IV } & 32(10.6) & 33(10.9) & \\ \text { Unstable angina, } \mathrm{n}(\%) & 9(3.0) & 11(3.2) & 0.655 \\ \text { Critical preoperative state, n (\%) } & 9(3.0) & 8(2.6) & 0.808 \\ \text { Frailty (moderate-severe), n (\%) } & 47(15.6) & 48(15.9) & 0.907 \\ \text { Urgent procedure, n }(\%) & 9(3.0) & 10(3.3) & 0.819 \\ \text { Logistic EuroSCORE I }(\% \pm \mathrm{SD}) & 9.3 \pm 8.0 & 9.4 \pm 6.8 & 0.853 \\ \text { Logistic EuroSCORE II }(\% \pm \mathrm{SD}) & 4.8 \pm 4.9 & 5.0 \pm 4.3 & 0.494\end{array}$

Abbreviations: SAVR, surgical aortic valve replacement; TAVI, transcatheter aortic valve implantation; BMI, body mass index; AMI, acute myocardial infarction; eGFR, estimated glomerular filtration rate; PCI, percutaneous coronary intervention; BAV, balloon aortic valvuloplasty; NYHA, New York Heart Association. *: according to the World Health Organization criteria (7). P-values refer to McNemar test for dichotomous variables, Stuart-Maxwell test for categorical variables and t-test for paired sample for continuous variables. 
Table 3. Preoperative echocardiographic parameters of propensity score matched pairs of patients with anemia undergoing transcatheter (TAVI) or surgical aortic valve replacement (SAVR).

\begin{tabular}{llll}
\hline & SAVR & TAVI & p-value \\
& $\mathrm{n}=302$ & $\mathrm{n}=302$ & \\
\hline LVEF, $\mathrm{n}(\%)$ & & & 0.851 \\
$>50 \%$ & $234(77.5)$ & $230(76.2)$ & \\
$30-50 \%$ & $60(19.9)$ & $62(20.5)$ & \\
$<30 \%$ & $8(2.6)$ & $10(3.3)$ & \\
Mitral valve regurgitation, $\mathrm{n}(\%)$ & & & \\
Moderate & $63(20.9)$ & $63(20.9)$ & \\
Severe & $8(2.6)$ & $4(1.3)$ &
\end{tabular}

Aortic valve pattern

$\begin{array}{llll}\text { Aortic valve area }\left(\mathrm{cm}^{2} \pm \mathrm{SD}\right) & 0.7 \pm 0.2 & 0.7 \pm 0.3 & 0.542 \\ \text { Peak gradient }(\mathrm{mmHg} \pm \mathrm{SD}) & 84 \pm 24 & 83 \pm 23 & 0.525 \\ \text { Mean gradient }(\mathrm{mmHg} \pm \mathrm{SD}) & 52 \pm 16 & 51 \pm 15 & 0.606 \\ \text { Annulus diameter }(\mathrm{mm} \pm \mathrm{SD}) & 21.1 \pm 2.2 & 22.2 \pm 2.1 & <0.0001\end{array}$

Abbreviations: SAVR, surgical aortic valve replacement; TAVI, transcatheter aortic valve implantation; LVEF, left ventricular ejection fraction. P-values refer to McNemar test for dichotomous variables, Stuart-Maxwell test for categorical variables and t-test for paired sample for continuous variables. 
Table 4. Early outcome endpoints in propensity score matched pairs of patients with anemia after transcatheter (TAVI) and surgical aortic valve replacement (SAVR).

\begin{tabular}{|c|c|c|c|}
\hline \multirow{2}{*}{ Adverse events } & \multirow{2}{*}{$\begin{array}{l}\text { SAVR } \\
\mathrm{n}=302\end{array}$} & \multicolumn{2}{|l|}{ TAVI } \\
\hline & & $\mathrm{n}=302$ & p-value \\
\hline 30 days mortality, $\mathrm{n}(\%)$ & $11(3.6)$ & $10(3.3)$ & 0.808 \\
\hline Stroke, n (\%) & $4(1.3)$ & $6(2.0)$ & 0.527 \\
\hline Valve migration, $\mathrm{n}(\%)$ & 0 & $5(1.7)$ & 0.074 \\
\hline Cardiogenic shock, n (\%) & $20(6.8)$ & $6(2.0)$ & 0.003 \\
\hline Cardiac tamponade, n (\%) & $12(4.1)$ & $8(2.7)$ & 0.371 \\
\hline Permanent pacemaker, n (\%) & $9(3.0)$ & $55(18.6)$ & $<0.0001$ \\
\hline Major vascular damage, n (\%) & $1(0.4)$ & $16(5.7)$ & $<0.0001$ \\
\hline Infection & & & 0.266 \\
\hline Wound, n (\%) & $5(1.7)$ & $4(1.2)$ & \\
\hline Lung or other organs, $\mathrm{n}(\%)$ & $9(3.1)$ & $16(5.6)$ & \\
\hline Sepsis, n (\%) & $6(2.1)$ & $2(0.7)$ & \\
\hline Emergency PCI, n (\%) & 0 & 0 & - \\
\hline $\mathrm{RBC}$ transfusion, $\mathrm{n}(\%)$ & $203(70.0)$ & $112(38.6)$ & $<0.0001$ \\
\hline $\mathrm{RBC}$ transfusion, $($ mean $\pm \mathrm{SD})$ & $2.7 \pm 3.6$ & $0.8 \pm 1.5$ & $<0.0001$ \\
\hline $\mathrm{RBC}$ transfusion $¥,($ mean $\pm \mathrm{SD})$ & $3.2 \pm 3.8$ & $1.1 \pm 1.5$ & 0.002 \\
\hline Paravalvular regurgitation, $\mathrm{n}(\%)$ & $28(9.3)$ & $143(47.4)$ & $<0.0001$ \\
\hline Mild & $23(8.0)$ & $125(43.7)$ & \\
\hline Moderate & $3(1.0)$ & $18(6.3)$ & \\
\hline Severe & $2(0.7)$ & 0 & \\
\hline AKIN stages & $142(50.7)$ & $78(27.9)$ & $<0.0001$ \\
\hline Stage $1 *$ & $85(30.4)$ & $54(19.3)$ & \\
\hline Stage $2 *$ & $15(5.3)$ & $6(2.1)$ & \\
\hline Stage $3 *$ & $42(15.0)$ & $18(6.4)$ & \\
\hline De novo dialysis, $\mathrm{n}(\%)^{*}$ & $34(11.8)$ & $15(5.2)$ & 0.005 \\
\hline
\end{tabular}




$\begin{array}{llll}\text { Mean transvalvular gradient }(\mathrm{mmHg} \pm \mathrm{SD}) & 13.2 \pm 6.5 & 10.6 \pm 6.4 & <0.0001 \\ \text { Peak transvalvular gradient }(\mathrm{mmHg} \pm \mathrm{SD}) & 24.5 \pm 11.1 & 19.5 \pm 10.8 & <0.0001 \\ \text { ICU stay (days } \pm \mathrm{SD}) & 4.7 \pm 9.6 & 3.2 \pm 4.3 & 0.012\end{array}$

Abbreviations: SAVR, surgical aortic valve replacement; TAVI, transcatheter aortic valve implantation; PCI,

percutaneous coronary intervention; ICU, intensive care unit; RBC, red blood cell; AKIN: Acute Kidney Injury

Network; *excluding patients with previous dialysis. P-values refer to McNemar test for dichotomous variables, Stuart-

Maxwell test for categorical variables and t-test for paired sample for continuous variables. ¥ Excluding patients who did not receive red blood cell transfusion. 
Table 5. Adverse events at 3 years after transcatheter (TAVI) and surgical aortic valve replacement (SAVR) in propensity score matched pairs of patients with anemia.

\begin{tabular}{lcc}
\hline Late events & SAVR & TAVI \\
& $\mathrm{n}=302$ & $\mathrm{n}=302$ \\
\hline Death from any cause & $26.0 \%$ & $33.7 \%$ \\
Stroke & $6.9 \%$ & $12.2 \%$ \\
Myocardial infarction & $5.0 \%$ & $4.1 \%$ \\
Coronary revascularization & $2.3 \%$ & $1.4 \%$ \\
MACCE & $32.4 \%$ & $41.3 \%$
\end{tabular}

\begin{abstract}
Abbreviations: SAVR, surgical aortic valve replacement; TAVI, transcatheter aortic valve implantation; MACCE, major adverse cardiac and cardiovascular events (defined as the composite of death from any cause, stroke, acute myocardial infarction and/or coronary revascularization).
\end{abstract}

Data are reported as actuarial estimates at the specific time point. 


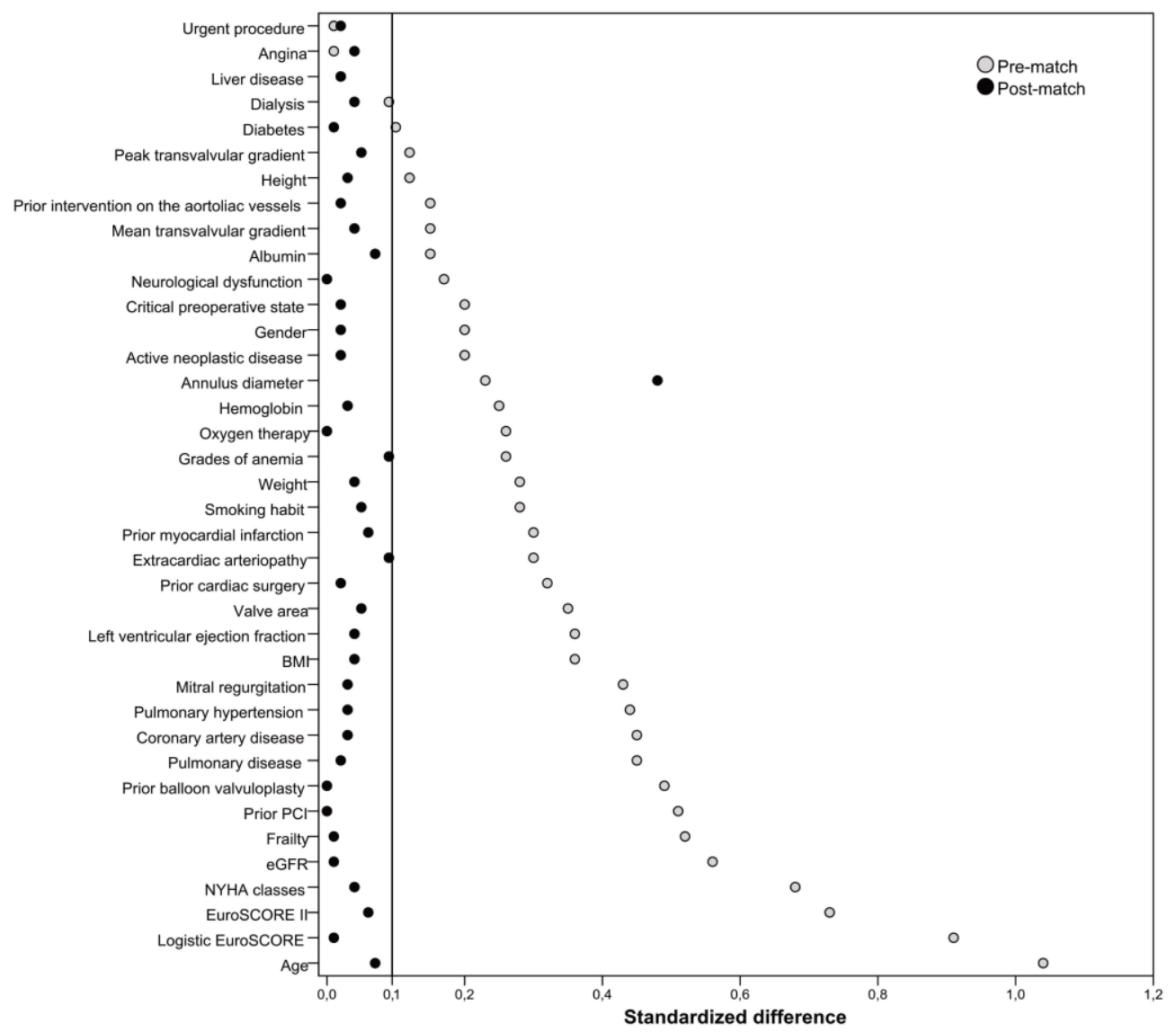



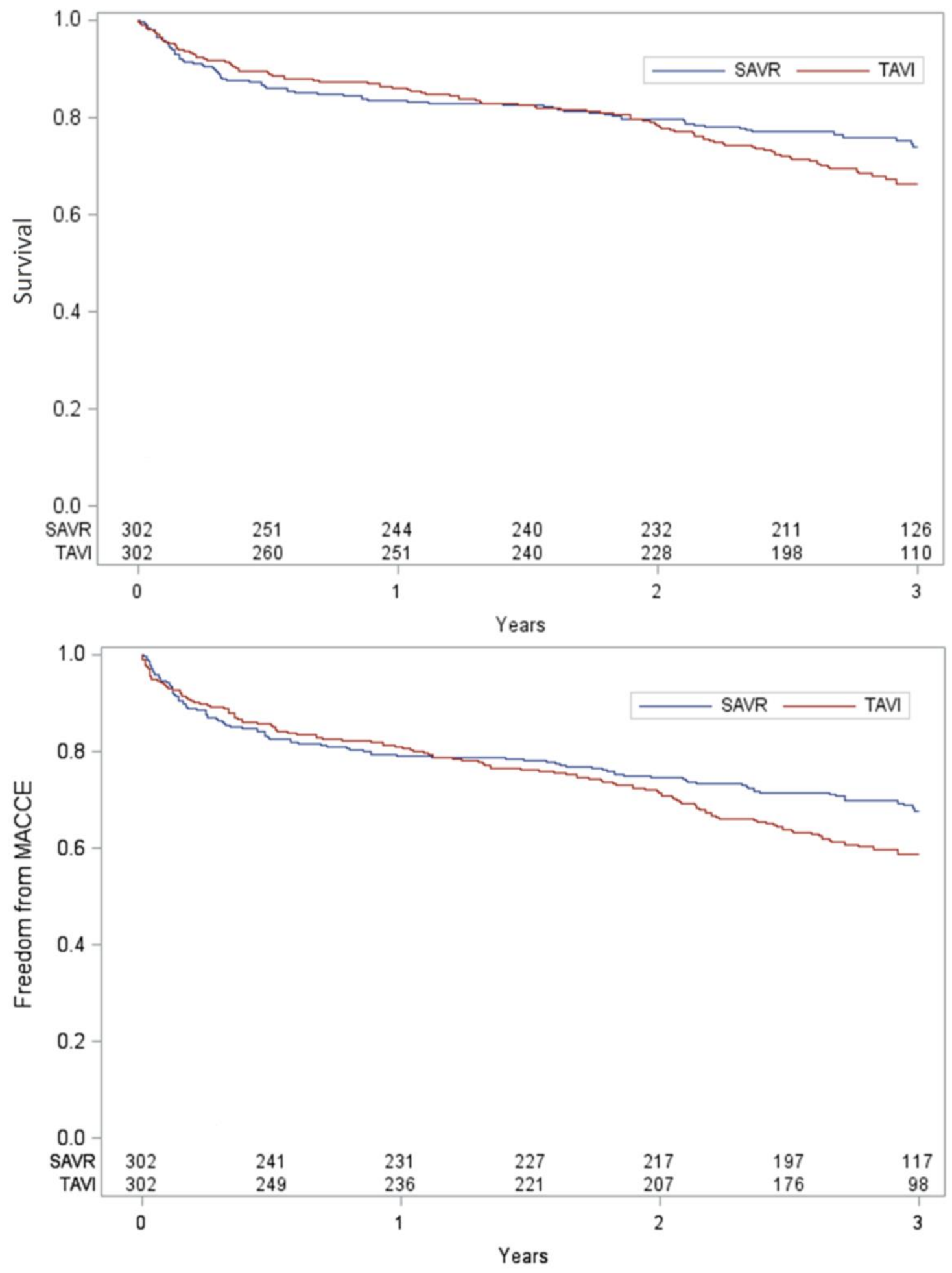


\section{APPENDIX}

\section{OBSERVANT Research Group,}

Fulvia Seccareccia, Paola D’Errigo, Stefano Rosato, Alice Maraschini, Gabriella Badoni, National Centre for Epidemiology, Surveillance and Health Promotion - ISS; Corrado Tamburino, Marco Barbanti, SICI-GISE, Gennaro Santoro, FIC, ANMCO; Francesco Santini, Francesco Onorati, Claudio Grossi, SICCH; Marco Ranucci, Remo Daniel Covello, ITACTA; Danilo Fusco, Epidemiology Dept. Lazio Region; Rossana De Palma, Emilia Romagna Region; Salvatore Scondotto, Sicilia Region.

\section{Participating hemodynamic centers}

1. A.O.U. Molinette - San Giovanni Battista di Torino, Torino. Marra S., D'Amico M.

2. A.O.U. Molinette - San Giovanni Battista di Torino, Torino. Gaita F., Moretti C.

3. Ospedale Mauriziano "Umberto I", Torino. De Benedictis M., Aranzulla T.

4. A.O. Nazionale Ss. Antonio e Biagio e Cesare Arrigo, Alessandria. Pistis G., Reale M.

5. Istituto Clinico S.Ambrogio, Milano. Bedogni F., Brambilla N.

6. Fondazione San Raffaele del Monte Tabor, Milano. Colombo A., Chieffo A., Ferrari A.

7. I.R.C.C.S. Policlinico San Donato, San Donato M.se (MI). Inglese L., Casilli F.

8. Spedali Civili di Brescia - Università, Brescia. Ettori F., Frontini M.

9. Ospedale Luigi Sacco - A.O. - Polo Universitario, Milano. Antona C., Piccaluga E.

10. A.O. Ospedale Niguarda Cà Granda, Milano. Klugmann S., De Marco F.

11. A.O. Bolognini Seriate, Seriate (BG). Tespili M., Saino A.

12. Ospedale "S. Maria di Ca' Foncello", Treviso. Franceschini Grisolia E.

13. A.O. di Padova, Padova. Isabella G., Fraccaro C.

14. A.O.U. Santa Maria Della Misericordia di Udine, Udine. Proclemer A., Bisceglia T., Armellini I.

15. A.O.U. San Martino, Genova. Vischi M., Parodi E.

16. A.O.U. Pisana, Pisa. Petronio S., Giannini C.

17. A.O.U. Senese Le Scotte, Siena. Pierli C., Iadanza A.

18. A.O.U. Careggi, Firenze. Santoro G., Meucci F.

19. European Hospital, Roma. Tomai F., Ghini A.

20. Policlinico Umberto I, Roma. Sardella G., Mancone M.

21. A.O.U. Integrata Verona, Verona. Ribichini F., Vassanelli C., Dandale R.

22. A.O.OO.RR.S. Giovanni di Dio e Ruggi d`Aragona - A.O.U. di Salerno, Salerno. Giudice P., Vigorito F.

23. A.O.U. Consorziale Policlinico di Bari, Bari. Bortone A., De Luca Tupputi Schinosa L., De Cillis E.

24. A.O.U. Mater Domini, Catanzaro. Indolfi C., Spaccarotella C.

25. A.R.N.A.S. Ospedale Civico - Di Cristina - Benfratelli, Palermo. Stabile A., Gandolfo C.

26. A.O.U. Policlinico - Vittorio Emanuele - Ospedale Ferrarotto, Catania. Tamburino C., Barbanti M., Ussia G.P.,

\section{Participating cardiac surgery centers}


1. A.O.U. Molinette - San Giovanni Battista di Torino, Torino. Rinaldi M., Salizzoni S.

2. A.O. S. Croce e Carle, Cuneo. Grossi C., Di Gregorio O.

3. A.O. Nazionale Ss. Antonio e Biagio e Cesare Arrigo, Alessandria. Scoti P., Costa R.

4. Ospedale Mauriziano "Umberto I", Torino. Casabona R., Del Ponte S.

5. Istituto Clinico S.Ambrogio, Milano. Panisi P., Spira G.

6. Fondazione Poliambulanza Istituto Ospedaliero, Brescia. Troise G., Messina A.

7. Fondazione I.R.C.S.S. Policlinico San Matteo, Pavia. Viganò M., Aiello M.

8. Fondazione San Raffaele del Monte Tabor, Milano. Alfieri O., Denti P.

9. I.R.C.C.S. Policlinico San Donato, San Donato M.se (MI). Menicanti L., Agnelli B.

10. Spedali Civili di Brescia - Università, Brescia. Muneretto C., Frontini M.

11. Spedali Civili di Brescia - Università, Brescia. Rambaldini M., Frontini M.

12. A.O. Ospedale di Lecco - Presidio Alessandro Manzoni, Lecco. Gamba A., Tasca G.

13. Ospedali Riuniti di Bergamo - A.O., Bergamo. Ferrazzi P., Terzi A.

14. Ospedale Luigi Sacco - A.O. - Polo Universitario, Milano. Antona C., Gelpi G.

15. A.O. Ospedale Niguarda Cà Granda, Milano. Martinelli L., Bruschi G.

16. Presidio Ospedaliero S.Chiara - Ospedale di Trento, Trento. Graffigna A.C.

17. A.O.U. Integrata Verona, Verona. Mazzucco A.

18. A.O.U. Ospedali Riuniti di Trieste - Ospedale di Cattinara, Trieste. Pappalardo A., Gatti G.

19. A.O.U. Santa Maria Della Misericordia di Udine, Udine. Livi U., Pompei E.

20. A.O.U. San Martino, Genova. Passerone G., Parodi E.

21. A.O.U. Pisana, Pisa. Bortolotti U., Pratali S.

22. A.O.U. Careggi, Firenze. Stefano P., Blanzola C.

23. Ospedale del Cuore G. Pasquinucci, Montepepe (MS). Glauber M., Cerillo A., Chiaramonti $\mathrm{F}$.

24. A.O. Santa Maria, Terni. Pardini A., Fioriello F.

25. A.O. G. M. Lancisi, Ancona. Torracca L., Rescigno G.

26. European Hospital, Roma. De Paulis R., Nardella S.

27. A.O. S Camillo-Forlanini, Roma. Musumeci F., Luzi G.

28. Policlinico Gemelli, Roma. Possati G., Bonalumi G.

29. Università Campus Bio-Medico di Roma, Roma. Covino E., Pollari F.

30. A.O. Sant'Andrea, Roma. Sinatra R., Roscitano A.

31. Policlinico Tor Vergata, Roma. Chiariello L., Nardi P.

32. Clinica San Michele, Maddaloni (CS). Lonobile T., Baldascino F.

33. A.O.OO.RR.S. Giovanni di Dio e Ruggi d`Aragona - A.O.U. di Salerno, Salerno. Di Benedetto G., Mastrogiovanni G.

34. A.O. San Sebastiano, Caserta. Piazza L., Marmo J.

35. A.O.U. Federico II, Napoli. Vosa C., De Amicis V.

36. Azienda Sanitaria Locale Le Fazzi Presidio Ospedaliero Vito Fazzi, Lecce. Villani M., Pano M.A.

37. S. Anna Hospital, Catanzaro. Cassese M., Antonazzo A.

38. Centro Cuore Morgagni, Pedara (CT). Patanè L., Gentile M., Tribastone S.

39. A.R.N.A.S. Ospedale Civico - Di Cristina - Benfratelli, Palermo. Follis F., Montalbano G.

40. IS.ME.T.T. (Istituto Mediterraneo per i Trapianti e Terapie ad Alta Specializzazione), Palermo. Pilato M., Stringi V.

41. A.O. Ospedali Riuniti Papardo - Piemonte, Messina. Patanè F., Salamone G.

42. A.O.U. Policlinico Paolo Giaccone, Palermo. Ruvolo G., Pisano C.

43. A.O.U. Policlinico - Vittorio Emanuele - Ospedale Ferrarotto, Catania. Mignosa C., Bivona A.

44. A.O. Brotzu, Cagliari. Cirio E.M., Lixi G. 
